\title{
Seed-dispersal networks are more specialized in the Neotropics than in the Afrotropics
}

\author{
Phillip J. Dugger $^{1}$ (i) | Pedro G. Blendinger ${ }^{2}$ | Katrin Böhning-Gaese ${ }^{3,4}$ | \\ Lackson Chama $^{5}$ | Marta Correia ${ }^{6}$ | D. Matthias Dehling7 | Carine Emer ${ }^{8}$ | \\ Nina Farwig $^{9}$ | Evan C. Fricke ${ }^{10}$ | Mauro Galetti ${ }^{8}$ | Daniel García ${ }^{11}$ | Ingo Grass ${ }^{12}$ | \\ Ruben Heleno $^{6}$ | Fábio A. F. Jacomassa ${ }^{13,14}$ | Suelen Moraes ${ }^{15}$ | Catherine Moran ${ }^{16}$ | \\ Marcia C. Muñoz ${ }^{17}$ | Eike Lena Neuschulz ${ }^{3}$ | Larissa Nowak ${ }^{3,4}$ | Augusto Piratelli ${ }^{15}$ | \\ Marco A. Pizo ${ }^{13}$ | Marta Quitián ${ }^{3,4}$ | Haldre S. Rogers ${ }^{10}$ | Román A. Ruggera ${ }^{18}$ | \\ Francisco Saavedra $^{19}$ | Mariano S. Sánchez ${ }^{20,21}$ | Rocío Sánchez ${ }^{2}$ | Vinicio Santillán ${ }^{3,4}$ | \\ Dana G. Schabo $^{9}$ | Fernanda Ribeiro da Silva ${ }^{22}$ | Sérgio Timóteo ${ }^{6}$ | Anna Traveset $^{23}$ | \\ Maximilian G. R. Vollstädtt ${ }^{3,4}$ (D) | Matthias Schleuning ${ }^{3}$ (D)
}

${ }^{1}$ Department of Environmental Studies, Antioch University New England, Keene, New Hampshire

${ }^{2}$ Instituto de Ecología Regional, Universidad Nacional de Tucumán-Consejo Nacional de Investigaciones Científicas y Técnicas, Yerba Buena, Argentina

${ }^{3}$ Senckenberg Biodiversity and Climate Research Centre (SBiK-F), Frankfurt am Main, Germany

${ }^{4}$ Institute for Ecology, Evolution and Diversity, Goethe University, Frankfurt am Main, Germany

${ }^{5}$ School of Natural Resources, Department of Zoology and Aquatic Sciences, Copperbelt University, Kitwe, Zambia

${ }^{6}$ Centre for Functional Ecology, Department of Life Sciences, University of Coimbra,

Coimbra, Portugal

${ }^{7}$ Centre for Integrative Ecology, School of Biological Sciences, University of Canterbury, Christchurch, New Zealand

${ }^{8}$ Instituto de Biociências, Departmento de Ecologia, Universidade Estadual Paulista, Rio Claro, Brazil

${ }^{9}$ Faculty of Biology, Philipps-University Marburg, Marburg, Germany

${ }^{10}$ Department of Ecology, Evolution \& Organismal Biology, lowa State University, Ames, lowa

${ }^{11}$ Departamento de Biología de Organismos y Sistemas, Universidad de Oviedo, and Unidad Mixta de Investigación en Biodiversidad (CSIC-UO-PA), Oviedo, Spain

\section{Abstract}

Aim: Biogeographical comparisons of interaction networks help to elucidate differences in ecological communities and ecosystem functioning at large scales. Neotropical ecosystems have higher diversity and a different composition of frugivores and fleshy-fruited plants compared with Afrotropical systems, but a lack of intercontinental comparisons limits understanding of (a) whether plant-frugivore networks are structured in a similar manner, and (b) whether the same species traits define the roles of animals across continents.

Location: Afrotropics and Neotropics.

Time period: 1977-2015.

Taxa: Fleshy-fruited plants and frugivorous vertebrates.

Methods: We compiled a dataset comprising 17 Afrotropical and 48 Neotropical weighted seed-dispersal networks quantifying frugivory interactions between 1,091 fleshy-fruited plant and 665 animal species, comprising in total 8,251 interaction links between plants and animals. In addition, we compiled information on the body mass of animals and their degree of frugivory. We compared four standard network-level metrics related to interaction diversity and specialization, accounting for differences related to sampling effort and network location. Furthermore, we tested whether animal traits (body mass, degree of frugivory) differed between continents, whether these traits were related to the network roles of species and whether these relationships varied between continents.

Results: We found significant structural differences in networks between continents. Overall, Neotropical networks were less nested and more specialized than Afrotropical 
${ }^{12}$ Agroecology, Department of Crop Sciences, University of Goettingen, Göttingen, Germany

${ }^{13}$ Departamento de Zoologia, Universidade Estadual Paulista, Rio Claro, Brazil

${ }^{14}$ Departamento de Ciências Biológicas, Programa de Pós-Graduação em Biologia Evolutiva, Universidade Estadual do Centro Oeste, Guarapuava, Brazil

${ }^{15}$ Departamento de Ciências

Ambientais, CCTS, Universidade Federal de São Carlos, Sorocaba, Brazil

${ }^{16}$ Commonwealth Scientific and Industrial Research Organisation (CSIRO), Atherton, Queensland, Australia

${ }^{17}$ Instituto de Investigación de Recursos Biológicos Alexander von Humboldt, Avenida Circunvalar 16-20, Bogotá D.C., Colombia

${ }^{18}$ Facultad de Ciencias Agrarias, INECOAUNJu, CONICET, Jujuy, Argentina

${ }^{19}$ Herbario Nacional de Bolivia, Instituto de Ecología, Universidad Mayor de San Andrés, Bolivia

${ }^{20}$ Instituto de Biología Subtropical (IBS)-nodo Posadas, Concejo Nacional de Investigaciones Científicas y Técnicas (CONICET) - Universidad Nacional de Misiones (UNaM), Posadas, Argentina

${ }^{21}$ Laboratorio de Genética Evolutiva, Facultad de Ciencias Exactas, Posadas, Argentina

${ }^{22}$ Programa de Pós Graducação em Biologia Vegetal, Universidade Estadual de Campinas, Campinas, Brazil

${ }^{23}$ Global Change Research

Group, Mediterranean Institute of Advanced Studies (IMEDEA, CSIC-UIB), Esporles, Spain

\section{Correspondence}

Phillip J. Dugger, Department of

Environmental Studies Keene, Antioch

University New England, Keene, NH 03431,

USA.

Email: pdugger@antioch.edu

Editor: Naia Morueta-Holme

\section{1 | INTRODUCTION}

Species interactions are organized in complex ecological networks that influence the structure of ecological communities and are important for ecosystem functioning (Bascompte, Jordano, Melián, \& Olesen, 2003; Schleuning, Fründ, \& García, 2015). The structural organization of species interaction networks can contribute to community stability and increase the ability of communities to recover from perturbations (Bascompte \& Jordano, 2014). Given the importance of ecological networks for ecosystem functioning (Schleuning et al., 2015), there has been a growing interest in comparative macroecological studies of species interaction networks across large spatial scales (e.g., Dalsgaard et al., 2017; Schleuning et al., 2012; Sebastián-González, Dalsgaard, Sandel, \& Guimarães, 2015). Macroecological analyses that take advantage of the largescale variation in ecological, evolutionary and historical conditions can reveal how biogeographical legacies have shaped the structure of ecological networks (Kissling \& Schleuning, 2015; Traveset et al., 2016).

About $90 \%$ of plant species participate in plant-frugivore networks in tropical ecosystems around the world (Jordano, 2000), and mutualistic seed-dispersal interactions between plants and animals provide a vital contribution to plant recruitment and forest regeneration (Neuschulz, Mueller, Schleuning, \& Böhning-Gaese, 2016). Tropical plant-frugivore networks comprise diverse communities of plant and animal species (Fleming, Breitwisch, \& Whitesides, 1987; 
Kissling, Böhning-Gaese, \& Jetz, 2009) and are generally characterized by a low degree of specialization of plants and animals on specific interaction partners (Dalsgaard et al., 2017; Schleuning et al., 2012). Many species of tropical frugivores strongly depend on fruit in their diet (Kissling et al., 2009) and usually feed on a large variety of different fruit resource species (Dalsgaard et al., 2017). Such frugivores with a high degree of frugivory usually fulfil essential structural roles in plant-frugivore networks and are important for the structural robustness of ecological communities (Mello et al., 2014; Ruggera, Blendinger, Gomez, \& Marshak, 2016). In addition, morphological traits, such as body size, can be associated with species' roles within networks (Dehling, Jordano, Schaefer, BöhningGaese, \& Schleuning, 2016), but relatively little is known about the generality of the relationship between species traits and network roles across large scales (but see Sebastián-González, 2017).

Within the tropics, species diversity and taxonomic composition of plants and animals vary substantially, owing to differences in evolutionary and historical legacies among biogeographical regions (Carlucci et al., 2017; Jansson \& Davies, 2008). For example, the Afrotropics and Neotropics differ in their evolutionary history, owing to major extinction events in the Afrotropics and greater diversification of angiosperms in the Neotropics (Carlucci et al., 2017). Consequently, Neotropical ecosystems comprise a higher diversity of fleshy-fruited plants (Terborgh et al., 2016), avian frugivores (Fleming et al., 1987; Kissling et al., 2009) and small mammals (De Vivo \& Carmignotto, 2004). Moreover, it has been suggested that more animal species in the Neotropics have specialized on a fruit diet compared with the Afrotropics (Fleming et al., 1987; Snow, 1981) Higher plant diversity and degree of frugivory in the Neotropics suggest that Neotropical frugivores will, on average, interact with more plant partners than their African counterparts, which could lead to differences in overall network structure. For example, it has been shown that tropical networks that are dominated by animal species with a high degree of frugivory have a low degree of specialization and modularity (Schleuning et al., 2012, 2014 ). Previous macroecological studies of mutualistic networks have further shown that an increase in species richness tends to be associated with an increase in modularity and nestedness (Martín-Gonzalez et al., 2015; SebastiánGonzález et al., 2015). So far, macroecological studies of network structure, especially along latitudinal gradients (e.g., Schleuning et al., 2012, Sebastián-González et al., 2015), have revealed inconsistent results, for example, owing to analytical and conceptual differences among studies (Dalsgaard et al., 2017). Another explanation for the inconsistent patterns in these studies could be that latitudinal trends in network structure are altered by structural differences of networks among biogeographical regions.

To date, no study has tested how the differences between Afrotropical and Neotropical ecosystems influence the structure of plant-frugivore networks at both the network and the species level. Here, we address this knowledge gap and ask the two following questions. First, how does the structure of seed-dispersal networks differ between Afrotropical and Neotropical communities? We propose two alternative hypotheses. It might be that the diverse
Neotropical networks, comprising many animals with a high degree of frugivory, are more nested and less specialized than networks in the Afrotropics (Schleuning et al., 2012). Alternatively, the higher plant and frugivore diversity of Neotropical networks might enhance niche partitioning (Sebastián-González et al., 2015) and, thus, lead to lower nestedness and higher specialization in Neotropical compared with Afrotropical networks. Second, how do the network roles of species differ between the Afrotropics and Neotropics, and how are these species roles related to species traits in both regions? We expect that Neotropical frugivores will, on average, interact with more partners than Afrotropical frugivores. We generally expect that species with a high degree of frugivory will interact with more plant partners than species that feed on fruits only occasionally (Sebastián-González, 2017).

\section{2 | METHODS}

\section{1 | Seed-dispersal networks}

We used data from 65 networks of plant-frugivore interactions, including 17 Afrotropical and 48 Neotropical networks (Figure 1). This bias reflects the prevalence of seed-dispersal studies in the Neotropics, whereas other tropical regions are understudied (Escribano-Ávila, Lara-Romero, Heleno, \& Traveset, 2018). Most datasets were collected in forested habitats (12 Afrotropical and 45 Neotropical networks) but also covered savannah habitats, especially in the Afrotropics. All datasets included weighted interaction data, specifying the absolute frequencies of interactions between plants and animals. The networks did not include data on interaction efficiencies, but the frequency of interactions has been proposed to be a good proxy for the importance of animals for plants and vice versa (Vázquez, Morris, \& Jordano, 2005). For each network, we collected detailed information on the sampling method to account for these differences in the analyses. Datasets differed in sampling approaches, based on the type of animal group on which the study was focused (birds, mammals, or both), in how interaction data were collected (plant or animal focused) and in the total sampling hours (see Supporting Information Table S1). We additionally calculated sampling completeness for each network, as the ratio between the number of observed links and expected link richness based on the Chao estimator (Dalsgaard et al., 2017; see Supporting Information Table S1), which was unrelated to the number of sampling hours ( $r=$ $-.012, p=.925, n=65$ networks). Most of the Neotropical networks comprised solely avian frugivores (36 out of 48 networks), whereas nine networks comprised both mammals and birds, and three only mammals. African networks included four bird-exclusive networks, whereas the other 13 networks were formed by birds and mammals. Twenty-nine Neotropical networks were plant based (fruit-removal observations), four were animal based (fecal samples), and 15 included both methods. Sixteen Afrotropical networks used plantbased observations, whereas only one study used animal-based data. Neotropical networks generally had more sampling hours (median: 300 total sampling hours) compared with African networks (median: 
(a)

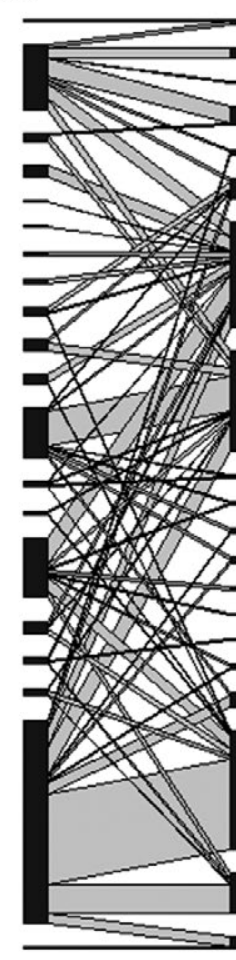

(c)

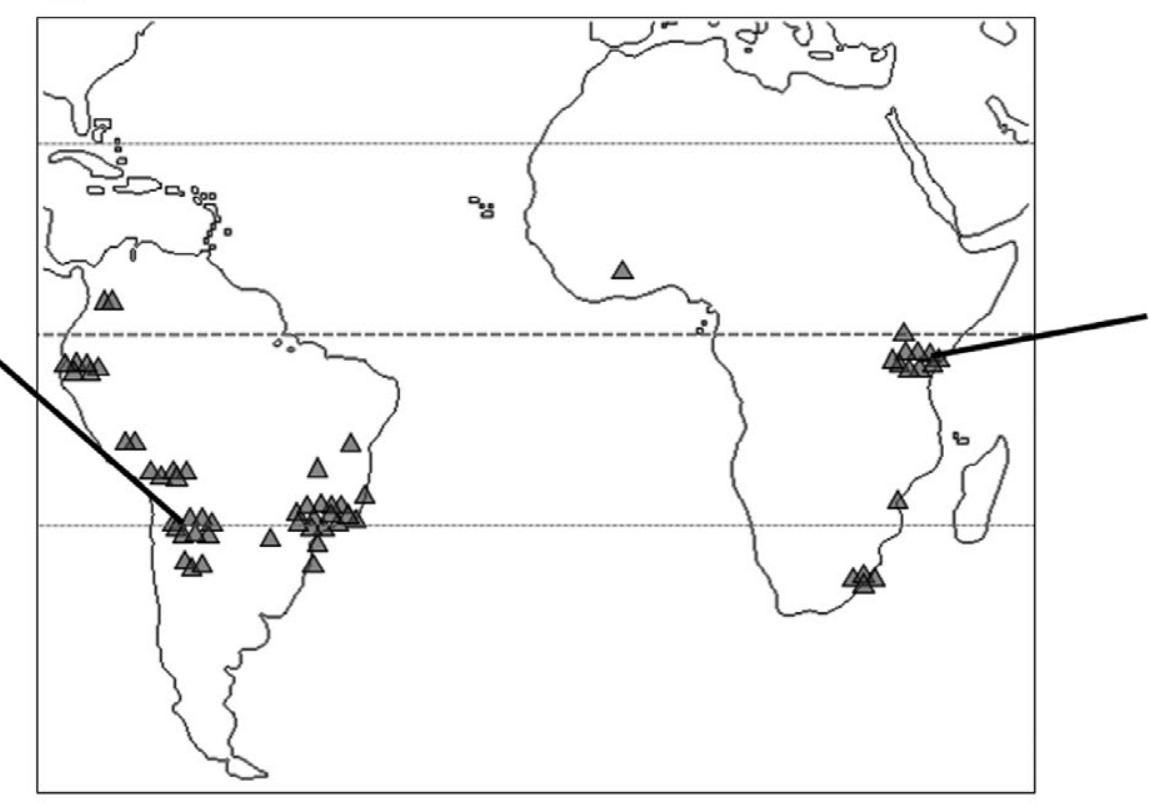

(b)

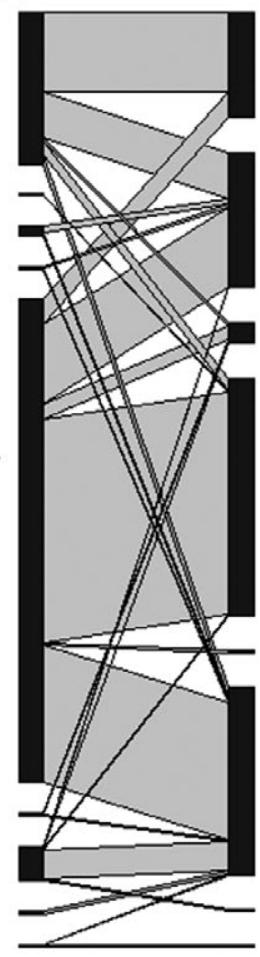

FIG URE 1 Bipartite graphs of example networks from (a) the Neotropics and (b) the Afrotropics. Black boxes denote plant species (left) and animal frugivores (right). Widths of boxes (black) and connecting lines (grey) denote the relative number of observed interactions. Bold lines indicate the approximate location of the corresponding study site for each network. The Neotropical network has been collected in Argentina (network ID = w37), the Afrotropical network in Tanzania (network ID = w59). (c) Spatial distribution of seed dispersal networks in the Neotropics and Afrotropics. Data were from 48 Neotropical networks and 17 Afrotropical networks. Dashed lines indicate the equator and the northern and southern limits of the tropics at $23.4^{\circ}$

125 total sampling hours; for details see Supporting Information Table S1). In order to account for potential biases owing to sampling differences, we accounted for sampling focus, method, hours and completeness in network-level analyses (Statistical analyses).

In addition to sampling differences, we compiled information to account for network-specific differences in study location and human impact. For each network, we recorded absolute latitude, elevation, level of current human disturbance (i.e., anthropogenic edge, fragmentation, degradation and defaunation), invasion (by introduced species) and species richness (total number of plant and animal species recorded in the network; see Supporting Information Table S1). Human disturbance and invasion levels at the time of data collection were estimated on an ordinal scale of one to four by the data providers, with one corresponding to the lowest disturbance and four to the highest (for details, see Supporting Information Table S2). Estimates of the different drivers of human disturbance were averaged for the analysis, yielding a single disturbance score ranging between one and four for each network.

For each animal species in the networks, we gathered information on species traits relevant to their role as frugivores (body mass; the proportion of fruit in the diet as an estimate of the degree of frugivory measured in $10 \%$ steps from $0 \%$ to $100 \%$ ) and taxonomy. For taxonomic information, we used the Clements taxonomic classification on Avibase for birds (Clements et al., 2016) and the IUCN Red
List classification for mammals (IUCN, 2016). Overall, we compiled taxonomic information for 51 mammal species and 614 bird species and combined that with data on body mass and the degree of frugivory (Wilman et al., 2014). We complemented trait data, when necessary, with information from other literature sources (e.g., Bello et al., 2017; Dunning, 2007).

\subsection{Network-level metrics}

We analysed interaction networks using the 'bipartite' package (Dormann, Gruber, \& Fruend, 2008) in R (R Core Team, 2016). Network-level metrics included weighted NODF (wNODF; a weighted measure of nestedness based on overlap and decreasing fill in a network matrix; Almeida-Neto et al., 2008), interaction evenness (EVE), quantitative modularity $(Q)$ and complementary specialization $\left(\mathrm{H}_{2}{ }^{\prime}\right)$. Nestedness quantifies the degree to which species with few interactions are connected to highly connected species and has been proposed to be associated with network stability (Bascompte et al., 2003). Weighted NODF accounts for interaction frequencies between species. Given that weighted NODF could underestimate nestedness owing to skewed distributions of interaction frequencies, we compared weighted NODF with two other nestedness metrics: weighted nestedness, an alternative weighted measure of nestedness, and binary NODF. Weighted NODF was significantly 
correlated with binary NODF (Pearson's correlation $r=.95, p<.001$, $n=65$ networks in all cases) and weighted nestedness (Pearson's correlation $r=.50, p<.001$ ), both of which yielded similar trends in biogeographical comparisons (Supporting Information Table S3). Interaction evenness measures the extent to which interactions are spread evenly across available partners, with high values indicating a more homogeneous distribution of interaction events across species (Bersier, Banašek-Richter, \& Cattin, 2002). Modularity analysis detects the degree to which certain groups of animals interact more often with a specific group of plants (and vice versa); that is, if species form tightly linked modules that are only weakly linked to species from other modules (Dormann \& Strauss, 2014). Modularity values are computed by detecting the extent to which the number of interactions between modules is lower than expected based on random interactions. We calculated modularity $Q$ with the algorithm proposed by Beckett (2016) for weighted bipartite networks based on a single model run with $10^{7}$ steps (Schleuning et al., 2014); five repeated runs yielded identical $Q$ values. Finally, $\mathrm{H}_{2}{ }^{\prime}$ measures the overall specialization within a network; that is, whether species in a network tend to partition or share their interaction partners (Blüthgen, Menzel, \& Blüthgen, 2006). The metric is calculated by a comparison between observed and expected interaction frequencies, based on the species marginal totals, and it is less sensitive to differences in sampling effort than other metrics (Blüthgen et al., 2006). High values of $H_{2}{ }^{\prime}$ and $Q$ indicate a high degree of niche partitioning among species or modules, respectively, whereas low values indicate a high degree of niche overlap among species or modules.

To test the extent to which the distribution of total interaction frequencies (i.e., marginal totals of species) influenced the biogeographical pattern, we additionally calculated null model-corrected metrics for weighted NODF, interaction evenness, modularity $Q$ values and $\mathrm{H}_{2}{ }^{\prime}$. We used 100 runs of the Patefield null model (Dormann et al., 2008), which constrains the marginal totals of the network matrix from both sides. For each network, we calculated null modelcorrected metrics ( $\triangle \mathrm{WNODF}, \Delta \mathrm{EVE}, \Delta \mathrm{Q}$ and $\Delta \mathrm{H}_{2}{ }^{\prime}$ ) as the difference between observed metrics and the mean value across the 100 null model runs (Dalsgaard et al., 2017). Observed and null model-corrected metrics were closely correlated for $Q(r=.77, p<.001)$ and $H_{2}{ }^{\prime}(r=.95, p<.001)$, but were only weakly related for interaction evenness ( $r=.19, p=.132)$ and weighted NODF $(r=.15, p=.232)$, confirming that nestedness strongly depends on the distribution of marginal totals (Blüthgen, Fründ, Vázquez, \& Menzel, 2008). If we used a null model that additionally constrained network connectance (Vázquez et al., 2007), patterns were similar, and the observed and null model-corrected metrics were significantly correlated for $Q$, $\mathrm{H}_{2}{ }^{\prime}$ and interaction evenness ( $r \geq .55, p<.001$ in all cases), whereas this was not the case for weighted NODF $(r=-.08, p=.548)$.

\section{3 | Species-level metrics}

We quantified the roles of animal species within networks by four species-level metrics that correspond to the employed networklevel metrics and are related to animal specialization on plants: normalized degree (ND), number of effective partners (EP), between-module connector values (c-values) and complementary specialization $\left(d^{\prime}\right)$. The normalized degree is the number of links of a species divided by the total number of possible links, thereby accounting for differences in network size (i.e., the number of plant partners relative to all potential plant partners in the respective network). Effective partners is a weighted measure of niche breadth that accounts for the frequency of interactions and equals the number of partners a species would have if each link was equally common; it is, thus, a weighted version of species degree (Bersier et al., 2002). Between-module connector values (c-values) determine the importance of a species in connecting different modules by interactions with species that are part of other modules, thereby reducing modularity (e.g., Schleuning et al., 2014). If the interactions of a species are evenly distributed among modules, it has a $c$-value close to one; if interactions are restricted to partners within a species' own module, the $c$-value is zero. Finally, complementary specialization $\left(d^{\prime}\right)$ measures the degree of specialization of a species by quantifying the niche exclusiveness of a species relative to a random distribution of interactions that is based on the marginal totals, analogous to the calculation of $\mathrm{H}_{2}{ }^{\prime}$ at the community level (Blüthgen et al., 2006).

\section{4 | Statistical analyses}

We compared the structure of interaction networks (described by network metrics wNODF, EVE, $Q$ and $\mathrm{H}_{2}{ }^{\prime}$ ) between the Afrotropics and Neotropics with linear models that account for network-specific differences in sampling and location. Covariates included sampling focus (plant, animal, or both), animal group (birds, mammals, or both), total sampling hours (log-transformed), sampling completeness, absolute latitude, elevation, disturbance and invasion level, and total species richness (log-transformed). We defined a full model including main effects of all covariates plus a factor of biogeographical region (Afrotropical versus Neotropical) that was included in all models. We compared all model combinations nested within this full model, according to the small sample size-corrected version of the Akaike information criterion (AICC), by using the dredge function ('MuMIn' package in R; Barton, 2016). We considered all models with a $\triangle \mathrm{AICc}$ value less than two (relative to the best model) to be equally supported and computed full model-averaged parameter estimates across the subset of best models (Burnham \& Anderson, 2002). We ran the same statistical analyses for the four null modelcorrected network metrics ( $\triangle \mathrm{WNODF}, \Delta \mathrm{EVE}, \Delta \mathrm{Q}$ and $\Delta \mathrm{H}_{2}{ }^{\prime}$ based on the Patefield algorithm).

To test how species roles, and their relationship with species traits, differed between biogeographical regions, we fitted linear mixed-effects models for each species-level metric (ND, EP, c-values and $d^{\prime}$, computed for all animal species within each network) with the 'Ime4' package (Bates, Maechler, Bolker, \& Walker, 2015). To account for the facts that networks differed in size and other properties, that species could occur in more than a single network and might not be evenly distributed taxonomically across networks, 
all models included network identity and taxonomic identity (taxonomic levels nested in this order: class, order, family and genus) as crossed random effects on the model intercepts. As fixed effects, we included biogeographical region, body mass (log-transformed) and the degree of frugivory (proportion of fruit in diet: $0 \%-100 \%$, in $10 \%$ steps) plus the two-way interaction between region $\times$ body mass and region $\times$ fruit diet. Hence, the model tested whether the two species' traits were similarly or differently related to specieslevel metrics in the two biogeographical regions. As in the analyses at the network level, we compared all model combinations nested within this full model (including all main and interaction effects of the fixed effects), selected a subset of best models according to their AICc, and computed full model-averaged parameter estimates across the subset of best models. In addition to models of species roles, we tested whether body mass and the degree of frugivory differed between biogeographical regions; that is, whether body mass and/or degree of frugivory were, on average, larger in one of the biogeographical regions. We fitted a mixed-effects model with the respective species trait as the response variable and biogeographical region as the predictor variable, accounting for network and taxonomic identity in the random model components as described above.
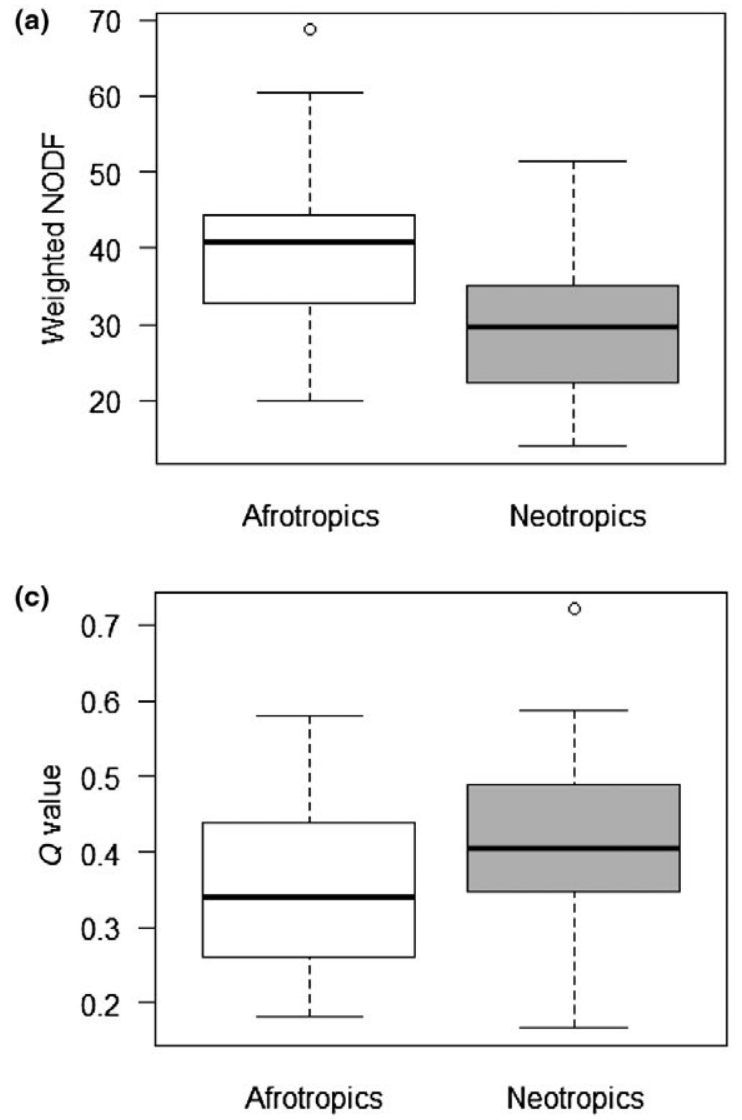

\section{3 | RESULTS}

Afrotropical networks included a total of 253 vertebrate frugivore species (mean species number per network $\pm S D=29.0 \pm 19.8$ ) from 142 genera in 44 families, and 257 fleshy-fruited plant species (mean, $29.9 \pm 22.1$ ) from 145 genera in 59 families. In comparison, Neotropical networks included a total of 412 vertebrate frugivore species (mean, $37.8 \pm$ 47.6) from 197 genera in 31 families, and 834 fleshy-fruited plant species (mean, $26.1 \pm 28.7$ ) from 242 genera in 90 families. In total, we recorded 8,251 links between plant and animal species across all networks, with 2,273 links recorded in the Afrotropics (mean, $133.7 \pm 120.4$ ) and 5,978 links in the Neotropics (mean, $124.5 \pm 147.2$ ). Across the 665 animal species, body mass ranged from 6.2 to $3,940,000 \mathrm{~g}$ (median, $31 \mathrm{~g}$ ), and the estimated proportion of fruit in the diet ranged from zero (i.e., species that had been classified as non-frugivorous) to $100 \%$ (median, 40\%).

\subsection{Network-level metrics}

When accounting for differences in sampling and locality (i.e., sampling focus, animal group, sampling hours, sampling completeness, absolute latitude, elevation, disturbance and invasion level, and

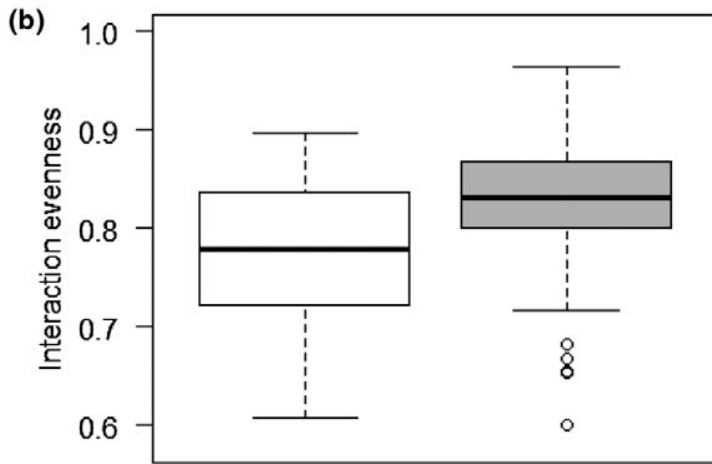

Afrotropics Neotropics

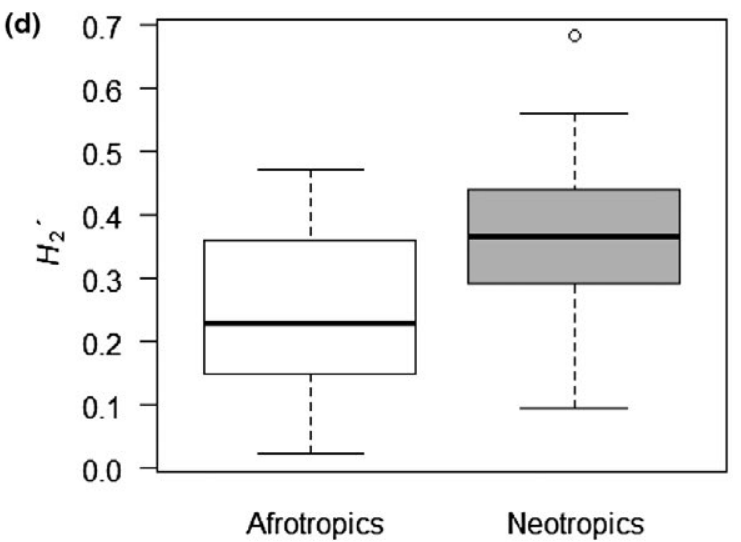

FIGURE 2 Differences in network-level metrics between Afrotropics and Neotropics, including: (a) weighted nestedness (wNODF); (b) interaction evenness; (c) modularity ( $Q$ value); and (d) complementary specialization $\left(H_{2}{ }^{\prime}\right)$. Here, 17 seed-dispersal networks from the Afrotropics were compared with 48 networks from the Neotropics. Shown are partial residuals plus model intercepts from the respective linear model (for statistical differences, see Table 1). Lines across boxes are medians, boxes denote 25th and 75th percentiles, whiskers indicate the data range, and circles denote outliers. 
TAB LE 1 Linear model estimates and standard errors for network-level metrics, including weighted nestedness (wNODF), interaction evenness, modularity (Q values) and complementary specialization $\left(H_{2}{ }^{\prime}\right)$

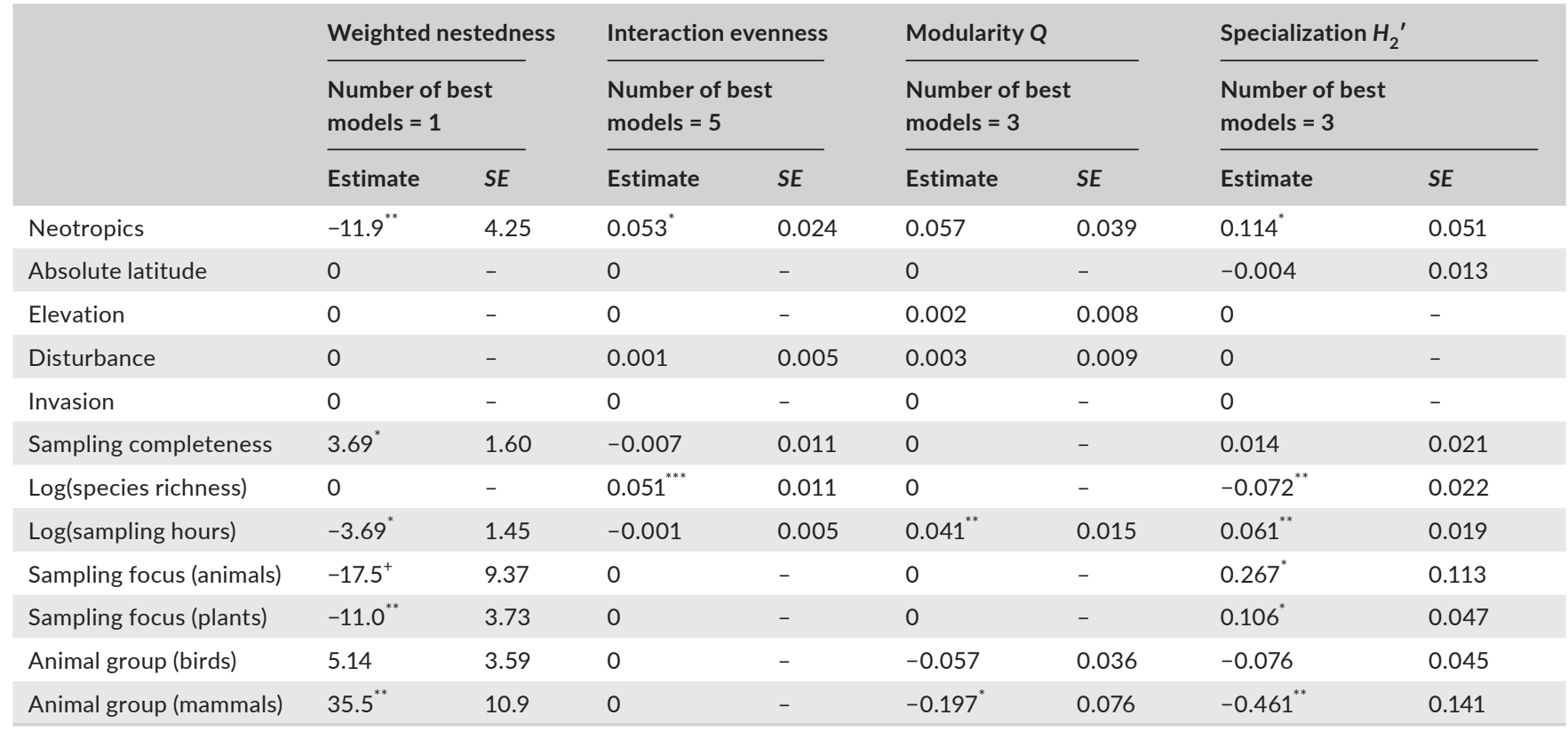

Note. For this analysis, 48 seed-dispersal interaction networks from the Neotropics were compared with 17 networks from the Afrotropics. Shown are estimates derived from model averaging over the subset of best models with $\Delta \mathrm{AlCc}<2$; estimates of zero indicate that the respective predictor was not included in the subset of best models. Sampling focus was tested as a factorial predictor at three levels: 'animals only', 'plants only' and 'both animals and plants'. Animal group was tested as a factorial predictor at three levels: 'birds', 'mammals' and 'both birds and mammals'. Continuous predictors [absolute latitude, elevation, disturbance, invasion, sampling completeness, species richness (log-transformed) and sampling hours (log-transformed)] were z-transformed.

${ }^{+} p<.1 .^{*} p<.05 .^{* *} p<.01 .^{* * *} p<.001$.

species richness), Afrotropical networks were significantly more nested than Neotropical networks (Figure 2a; Table 1). In addition, Afrotropical networks showed lower interaction evenness than Neotropical networks (Figure 2b; Table 1 ) and were significantly less specialized than Neotropical networks (Figure 2c; Table 1). There was no significant difference between biogeographical regions in network modularity (Figure 2d; Table 1). Analyses based on null model-corrected metrics yielded a similar, but non-significant trend for network specialization, and very weak intercontinental differences for interaction evenness, modularity and nestedness (Supporting Information Table S4).

Sampling strategy also influenced network-level metrics (Table 1). Networks sampled with an only-plant or only-animal sampling focus registered lower nestedness and higher complementary specialization than networks with a combined animal and plant focus. Networks including mammals as the only sampled animal group had higher nestedness and lower modularity and complementary specialization than networks including either only birds or both mammals and birds. Modularity and complementary specialization increased, whereas nestedness decreased with an increasing number of sampling hours. Furthermore, nestedness increased with increasing sampling completeness, while interaction evenness increased and complementary specialization decreased with increasing species richness (Table 1).

\section{2 | Species-level metrics}

Interaction data from the Afrotropics involved, in total, 34 mammal (24 genera, nine families, six orders) and 219 bird species (118 genera, 35 families, 10 orders), whereas we recorded interactions of 17 mammal (11 genera, three families, three orders) and 395 bird species (186 genera, 28 families, eight orders) in the Neotropics. In the Afrotropics, animal species had a significantly lower degree of frugivory than in the Neotropics (Figure 3a). In contrast, animal body mass was not significantly different between the two biogeographical regions, although the largest seed dispersers were present in the Afrotropics (Figure 3b).

By accounting for network identity and animal taxonomy, the roles of species within the networks varied as a function of species traits and biogeographical region. Normalized degree was significantly higher in the Afrotropics than in the Neotropics, especially for species with a high degree of frugivory (Figure 4a; Table 2). The number of effective plant partners, which accounts for differences in interaction frequencies among partners, did not differ significantly between biogeographical regions and increased in both biogeographical regions with body mass and an increasing degree of frugivory (Figure 4b; Table 2). The c-values increased with an increasing degree of frugivory, but only in the Afrotropics (Figure 4c; Table 2). Complementary specialization $\left(d^{\prime}\right)$ and degree of frugivory were 

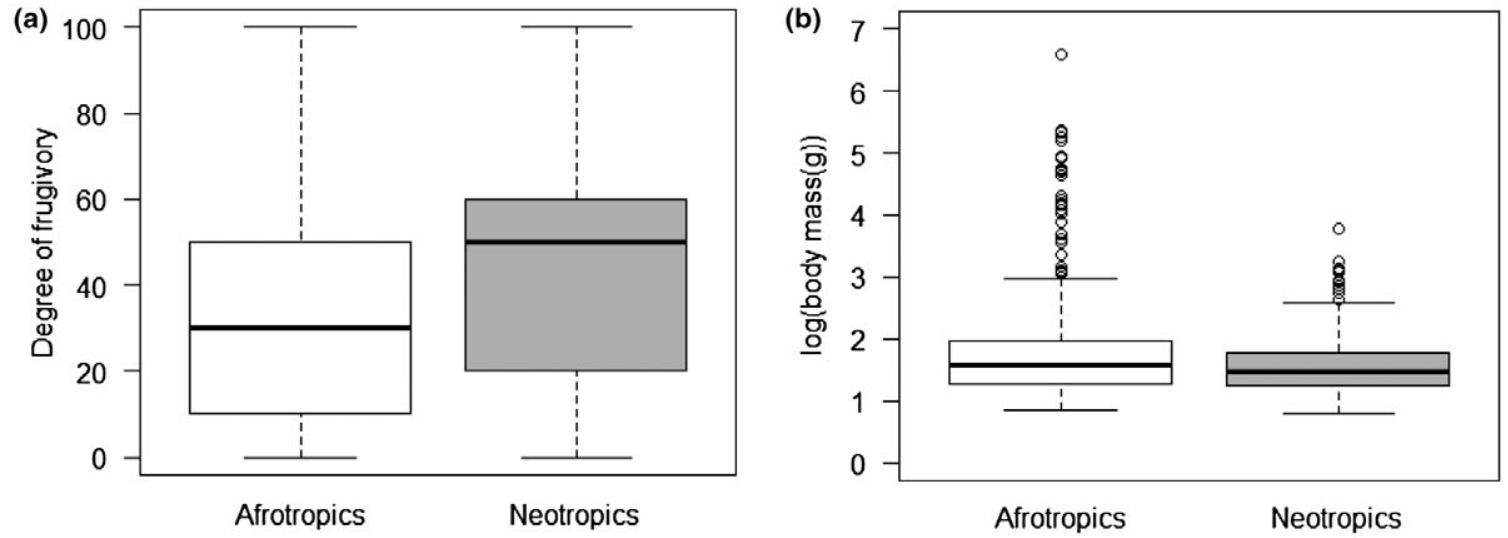

FIGURE 3 Differences in animal species traits between Afrotropics and Neotropics. Shown are differences in (a) the degree of frugivory (i.e., the proportion of fruit in diet, recorded in $10 \%$ steps) and (b) the body mass (log-transformed) between biogeographical regions. Analyses are based on 17 seed-dispersal networks from the Afrotropics and 48 networks from the Neotropics. Afrotropical networks included a total of 254 animal species from 197 genera in 31 families, Neotropical networks included a total of 411 animal species from 142 genera in 44 families. Estimates $( \pm S E$ ) from linear mixed-effects models accounting for taxonomic differences among animal species (taxonomic levels: class, order, family and genus): degree of frugivory, 13.10 ( \pm 2.69 ); body mass, .005 ( \pm .022 )

positively associated in the Neotropics, but showed a weak negative relationship in the Afrotropics (Figure 4d; Table 2). There were no significant interactions between body mass and biogeographical region for any of the species-level metrics (Table 2).

\section{4 | DISCUSSION}

Afrotropical and Neotropical networks differed in their topological structure, probably owing to the biogeographical differences in the diversity and composition of fleshy-fruited plants and animal frugivores between the two regions (Fleming et al., 1987; Jansson \& Davies, 2008; Kissling et al., 2009). Our results at the network level lent support to our second hypothesis that Neotropical networks are less nested and more specialized than Afrotropical networks. This finding was supported by analyses at the species level, in which we detected that a higher degree of frugivory was associated with an increasing diversity of explored food resources and a lower selectivity in food choices in the Afrotropics, whereas niche partitioning was greater among frugivores in Neotropical networks.

Afrotropical and Neotropical networks differed in network structure while controlling for potentially confounding factors, such as the sampling focus, the studied animal group and the locally recorded species richness. Higher nestedness and lower interaction evenness and complementary specialization in Afrotropical relative to Neotropical networks were, thus, independent of these differences in sampling. Analyses of null model-corrected metrics revealed that the differences in specialization between the two regions were mostly attributable to differences in the degree of selectivity by a species of distinct fruit resources, as corroborated by the high correlation between observed and null model-corrected values of complementary specialization. This confirms previous studies that have shown that complementary specialization is a sensitive indicator for structural differences among networks at large spatial scales (Blüthgen, Menzel, Hovestadt, Fiala, \& Blüthgen, 2007; Schleuning et al., 2012). In contrast, intercontinental differences in nestedness and interaction evenness were attributable to differences in the distribution of species' total interaction frequencies, which is consistent with previous comparative analyses of different types of network metrics (Blüthgen et al., 2008). Given that total interaction frequencies are related to resource availability and consumer activity, and thus also reflect variation in species abundances (Blüthgen et al., 2006), biogeographical patterns in these network metrics could be driven by differences in the abundance distributions of plants and animals on the two continents. Given that Neotropical ecosystems generally comprise a higher diversity of frugivores and fleshy-fruited plants than Afrotropical systems (Jansson \& Davies, 2008; Kissling et al., 2009), a lower proportion of abundant species and a larger proportion of uncommon and rare plant and animal species is expected for Neotropical systems, consistent with the reported decrease in nestedness and increase in interaction evenness in the Neotropics. Our findings were apparently different from those of previous macroecological studies of seed-dispersal networks. In macroecological studies along latitudinal gradients, nestedness generally increased (Sebastian-Gonzalez et al., 2015) and network specialization decreased (Dalsgaard et al., 2017; Schleuning et al., 2012) in diverse tropical systems. Unlike those studies, in the present study we focused on a comparison between biogeographical regions in tropical and subtropical ecosystems, and variation in latitude was unrelated to network structure (Table 1). Nevertheless, local species richness in the networks showed a consistent negative relationship to complementary specialization (Table 1; Supporting Information Table S4), which corresponds to patterns that have been reported previously (Schleuning et al., 2012).

We postulate that differences in network structure between Afrotropical and Neotropical networks are mostly attributable to 


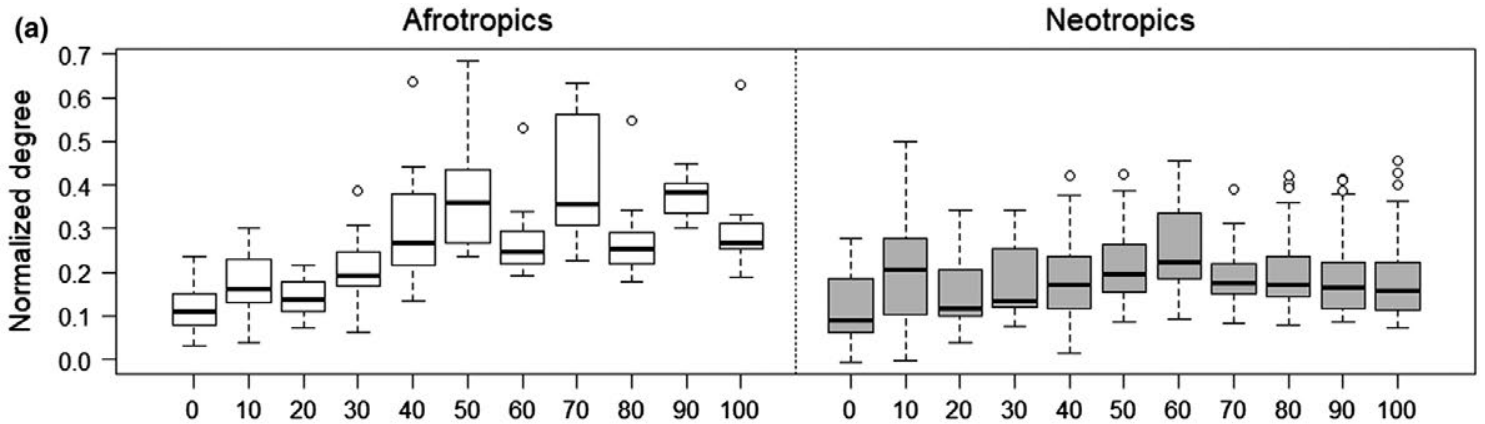

(b)

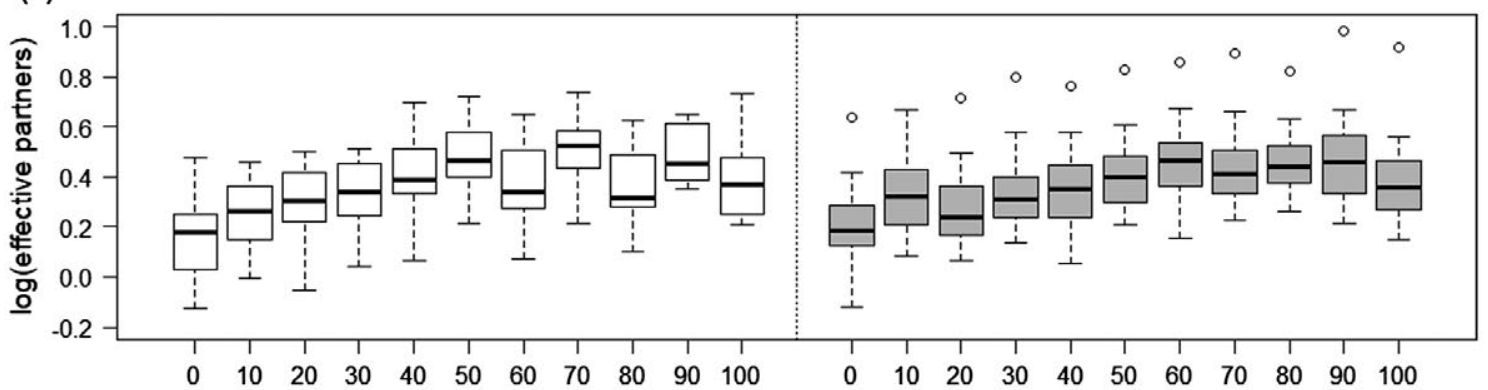

(c)

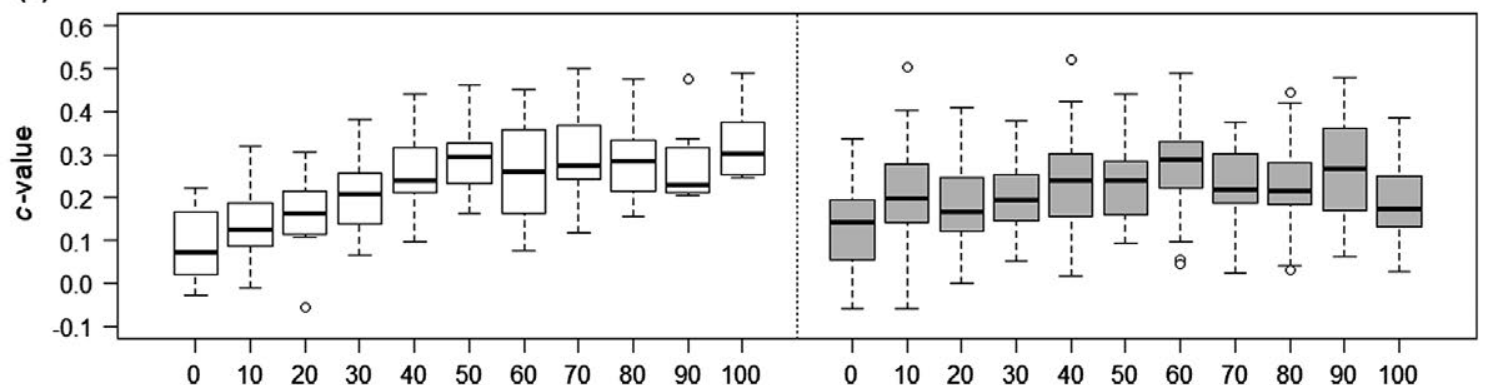

(d)

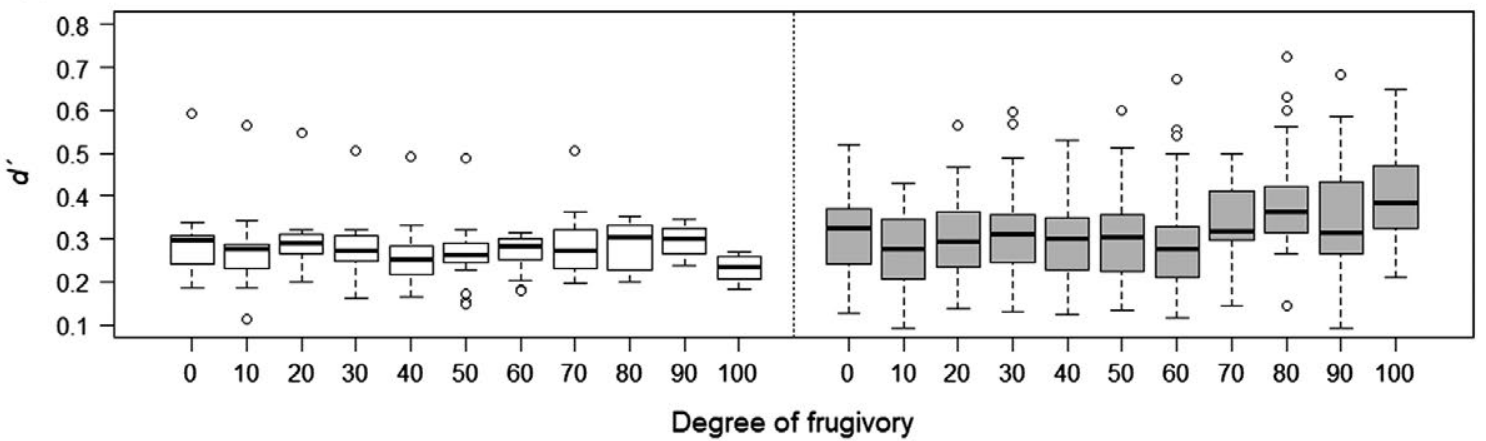

FIGURE 4 Relationships between species-level metrics and the degree of frugivory in Afrotropics and Neotropics. Shown are the fitted values according to model estimates from the respective linear mixed-effects models for: (a) normalized degree; (b) effective partners (logtransformed); (c) c-value; and (d) $d^{\prime}$ (see Table 2 for details). Box plots denote variation among networks in the Afrotropics and Neotropics; that is, for visualization the fitted values of the species-level metrics were averaged for each level of frugivory within each network

differences in how Afrotropical and Neotropical frugivores partition the available fruit resources. Afrotropical ecosystems generally harbour a comparatively low diversity of fleshy-fruited plants (Terborgh et al., 2016), which constrains the fruit choice of Afrotropical frugivores. Moreover, keystone fruit resources, such as the ubiquitous fig species in the Afrotropics (Kissling, Rahbek, \& Böhning-Gaese,
2007), favour animal aggregation and apparently result in a high degree of nestedness and niche overlap in these networks. In contrast, the higher diversity of fruit types in the Neotropics facilitates niche partitioning among Neotropical frugivores (Fleming et al., 1987) and could act as a mechanism that reinforces the high diversity of plants in Neotropical compared with Afrotropical forests (Terborgh et al., 
TAB LE 2 Estimates and standard errors of linear mixed-effects models for species-level metrics [normalized degree, effective partners, between-module connector value (c-value) and complementary specialization $\left.\left(d^{\prime}\right)\right]$ of animal species in seed-dispersal networks of the Afrotropics and Neotropics

\begin{tabular}{|c|c|c|c|c|c|c|c|c|}
\hline & \multirow{2}{*}{\multicolumn{2}{|c|}{$\begin{array}{l}\text { Normalized degree } \\
\text { Number of best } \\
\text { models = } 2\end{array}$}} & \multirow{2}{*}{\multicolumn{2}{|c|}{$\begin{array}{l}\text { Effective partners } \\
\text { Number of best } \\
\text { models = } 2\end{array}$}} & \multirow{2}{*}{\multicolumn{2}{|c|}{$\begin{array}{l}c \text {-value } \\
\text { Number of best } \\
\text { models }=2\end{array}$}} & \multirow{2}{*}{\multicolumn{2}{|c|}{$\begin{array}{l}\text { Specialization } d^{\prime} \\
\text { Number of best } \\
\text { models }=3\end{array}$}} \\
\hline & & & & & & & & \\
\hline & Estimate & $S E$ & Estimate & SE & Estimate & SE & Estimate & $S E$ \\
\hline Neotropics & $-0.085^{* *}$ & 0.031 & -0.028 & 0.050 & -0.046 & 0.034 & $0.068^{*}$ & 0.033 \\
\hline Frugivory $\times \mathrm{Neo}$ & $-0.051^{* * *}$ & 0.012 & -0.029 & 0.028 & $-0.048^{* *}$ & 0.017 & $0.033^{*}$ & 0.015 \\
\hline Body mass $\times \mathrm{Neo}$ & 0 & - & 0 & - & 0 & - & 0.003 & 0.010 \\
\hline
\end{tabular}

Notes. Analyses are based on 411 animal species from 48 networks in the Neotropics and 254 animal species from 17 networks in the Afrotropics. Shown are estimates derived by model averaging over the subset of best models with $\Delta \mathrm{AICc}<2$; estimates of zero indicate that the respective predictor was not included in the subset of best models. Fixed effects were the degree of frugivory (i.e., the proportion of fruit in the diet), body mass (in grams; log-transformed) and biogeographical region (Afrotropics versus Neotropics). Random effects were animal taxonomy (class, order, family and genus) and network identity. Estimates are comparable within each model because degree of frugivory and body mass were z-transformed. ${ }^{*} p<.05 .{ }^{* *} p<.01 .{ }^{* * *} p<.001$.

2016). Another explanation for the difference between continents could be that the frugivorous megafauna, such as primates or large ungulates, have a generalized diet (Campos-Arceiz \& Blake, 2011; Chancellor, Rundus, \& Nyandwi, 2017). The extinction of frugivorous megafauna from the Neotropical continent ca. 10,000 yr BP (Guimarães, Galetti, \& Jordano, 2008), which were probably also dietary generalists, could also be associated with lower nestedness and higher specialization in Neotropical than Afrotropical systems. Interestingly, our findings for seed-dispersal networks are consistent with a cross-continental study on avian plant-pollinator networks that found a higher degree of specialization in Neotropical than in Paleotropical plant-bird networks (Zanata et al., 2017). The high diversity of angiosperms in Neotropical ecosystems (Carlucci et al., 2017) may, thus, generally foster the potential for niche differentiation among mutualists in the Neotropics.

Greater functional redundancy among frugivores in the Afrotropics could foster the structural robustness of these networks, because a greater functional redundancy has been suggested to be associated with greater ecosystem stability (Schleuning et al., 2015). Neotropical communities might, in contrast, be more vulnerable to the loss of animal frugivores that fulfil rather complementary roles in these networks (Vidal et al., 2014). Several recent studies have demonstrated that the loss of frugivores from Neotropical communities leads to changes in gene flow, plant recruitment and carbon storage (e.g., Carvalho, Galetti, Colevatti, \& Jordano, 2016; Peres, Emilio, Schietti, Desmouliè, \& Levi, 2016). Peres et al. (2016) used field data to model the loss of dispersal functions from overhunting of large frugivores in the Brazilian Amazon and predicted losses of above-ground biomass of up to $30 \%$ in some locations. Carvalho et al. (2016) documented that defaunation of large frugivores can lead to microevolutionary changes in a Brazilian Atlantic Forest palm (Euterpe edulis) through the loss of dispersal functions from large seed dispersers, which can even result in a decrease in seed size in defaunated habitats
(Galetti et al., 2013). Functional consequences of the loss of generalist seed dispersers have been shown to be particularly severe, because these species help to stabilize seed-dispersal functions against the loss of specialists (Rumeu et al., 2017), although specialist seed dispersers cannot always be replaced by generalists (Guaraldo, Boeni, \& Pizo, 2013). Species loss could be buffered further by species that switch their preference to compensate for lost interactions (Timóteo, Albino Ramos, Vaughan, \& Memmott, 2016). A high plasticity of frugivores to temporal variation in fruit availability has been described for Neotropical seed-dispersal networks (Blendinger, Martín, Acosta, Ruggera, \& Aráoz, 2016). However, this flexibility in resource use is limited by morphological constraints, because large frugivores can feed on and potentially disperse a wider range of seeds than small frugivores; thus, small frugivores are unlikely to compensate functionally for the loss of large seed dispersers (Bender et al., 2017). Likewise, altered interaction patterns in response to competition could be to the detriment of plants with specialized interactions (Fricke, Tewksbury, \& Rogers, 2018), which is more likely to happen in systems with a high diversity, such as Neotropical ecosystems.

Although the higher degree of nestedness in Afrotropical networks could make them more robust against the loss of species, previous studies have demonstrated that the loss of frugivores in Africa can affect plant recruitment by disrupting mutualistic interactions between plants and their seed dispersers (Cordeiro \& Howe, 2003). Poulsen, Clark, and Palmer (2013) found that even partial defaunation in Afrotropical forests can lower dispersal distances of mammal-dispersed trees, and Correia, Timóteo, Rodríguez-Echeverría, Mazars-Simon, and Heleno (2016) highlighted the importance of large mammal dispersers for restoration of seed-dispersal functions in Africa. Nevertheless, comparative studies of African frugivore communities in disturbed forest habitats found a rather high robustness of bird-mediated seed dispersal to human impact (Farwig, Böhning-Gaese, \& Bleher, 2006; Neuschulz, Botzat, \& Farwig, 2011). 
These findings suggest a rather high degree of functional redundancy among bird dispersers, whereas the loss of mammal frugivores, such as primates or elephants, is likely to have severe ecological consequences, especially for large-seeded plants that depend on this megafauna (Campos-Arceiz \& Blake, 2011; Correia et al., 2016).

Species-level analyses indicate generally lower specialization in Afrotropical than in Neotropical networks, consistent with our findings at the network level. Across regions, the number of effective plant partners increased with the degree of frugivory, which is consistent with previous findings (Fricke, Tewksbury, Wandrag, \& Rogers, 2017; Schleuning et al., 2014). The increase in normalized degree and between-module connector values with the degree of frugivory was evident only in the Afrotropics, suggesting that highly frugivorous Afrotropical species use a large proportion of the available resources. This applies, for instance, to avian lineages with a high dependence on fruits in their diet, such as the African barbets (Lybiidae) or bulbuls (Pycnonotidae; Schleuning et al., 2014). The generalized foraging of these taxa results in overlapping resource use with other frugivores, especially at tropical latitudes (Dalsgaard et al., 2017). In the Neotropics, we found no association between the degree of frugivory and normalized degree or between-module connector values. This suggests that species with a mostly frugivorous diet have relatively more fruit resources to choose from in the Neotropics and show less resource overlap with other co-occurring species (Fleming et al., 1987). Indeed, we found that Neotropical species with a high degree of frugivory overlapped less in resource choice than species with fewer fruits in their diet. This suggests that the evolution of frugivory in the Neotropics trends towards specialization on specific fruit resources, which could have been reinforced by plant trait convergence in diverse mutualistic networks; that is, convergence of plant species on different fruit-trait syndromes could strengthen niche partitioning (Escribano-Ávila et al., 2018; Guimarães, Jordano, \& Thompson, 2011). This finding is also consistent with a high degree of trait matching between avian frugivores and their preferred foraging plants in the Neotropics (Bender et al., 2018). Although plants and frugivores in the Afrotropics show similar patterns of trait matching (Vollstädt et al., 2017), the higher resource diversity in the Neotropics should lead to higher resource specialization and niche partitioning in Neotropical frugivores.

Our findings show that frugivores in the Afrotropics, on average, fulfil more generalized functional roles than their Neotropical counterparts, because they disperse a larger proportion of the available resources. Generalization of Afrotropical frugivores might functionally compensate for the lower diversity of animal frugivores compared with the Neotropics. Interestingly, this trend towards a greater generalization in Afrotropical frugivores with a high fruit dependence was unrelated to body mass and, thus, is not a result of the generalized diet of large mammals only (CamposArceiz \& Blake, 2011; Chancellor et al., 2017), but fruit-dependent animals in the Afrotropics appear to be more generalized in their fruit resource use regardless of body size. Our findings corroborate earlier studies that have also shown that the degree of frugivory is generally a more important functional trait than body mass in seed-dispersal networks (Mello et al., 2014; Sebastián-González, 2017). The degree of frugivory could, therefore, be used as a useful proxy for the identification of keystone frugivores in tropical ecosystems, although such keystone species could differ in their functional roles depending on the specific ecological and regional context. For example, in less diverse networks, such as in most Afrotropical systems, generalized frugivores may play a crucial role in contributing to network robustness, whereas in more diverse networks, such as in many Neotropical systems, specialized frugivores are crucial for maintaining seed-dispersal functions to the entire plant community.

Our findings indicate important structural differences between Afrotropical and Neotropical seed-dispersal networks. We argue that these differences are a consequence of biogeographical differences in the diversification of frugivores and fleshy-fruited plants and differences in the persistence of frugivorous megafauna in the two regions. Regional differences were most pronounced for animal species with a high degree of frugivory that overlapped more in the use of fruit resources in the Afrotropics but were more specialized on specific resource species in the Neotropics. These differences might have important consequences for ecosystem functioning in both regions. In the Afrotropics, generalist frugivores are particularly crucial for maintaining seed-dispersal functions at plant community level. In the Neotropics, the extirpation of animal species with a high degree of frugivory is more likely to trigger the loss of seed-dispersal functions in plant communities unless functional flexibility of frugivores allows for the compensation of lost interactions.

\section{ACKNOWLEDGMENTS}

We thank Beth A. Kaplin and Norbert J. Cordeiro for their guidance and support for P.J.D., who received a travel grant by The Center for Tropical Studies and Conservation (CTEC). L.C. and I.G. were supported by the Robert Bosch Foundation. D.M.D. (DE 2754/1-1), F.S. (HE 3041/20-1), M.Q., V.S., E.L.N. (Research Unit 823-825), and K.B.G., M.S. and M.G.R.V. (FOR 1246) thank the German Research Foundation (DFG) for funding. F.A.F.J. acknowledges funding by a CAPES scholarship, N.F. and D.G.S. by the Robert Bosch Foundation, M.G., C.E., A.P. and M.A.P. by Fundação de Amparo à Pesquisa do Estado de São Paulo (FAPESP 2010/52315-7; 2015/15172-7; 2016/18355-8) and Conselho Nacional de Desenvolvimento Científico (CNPq), M.C.M. by Doctoral Fellowships from COLCIENCIAS and Rufford, M.S.S. by Consejo Nacional de Investigaciones Científicas y Técnicas (CONICET) and FONCYT (PICT2013-2759 and PICT2016-0608), P.G.B. by CONICET (PIP 2014-592) and FONCYT (PICT 2013-1280), R.A.R. by a Doctoral Fellowship from CONICET, R.H. and S.T. (IF/00441/2013) and M.C. (SFRH/BD/96050/2013) by Fundação para a Ciência e Tecnologia, Portugal, and A.T. (CGL2013-44386-P) and D.G. (CGL2015-68963C2-2-R) by the Spanish government. T. Hovestadt, K. McConkey and 
two anonymous reviewers commented on an earlier draft of this manuscript.

\section{AUTHOR CONTRIBUTIONS}

All authors provided interaction and trait data for this meta-analysis. P.J.D. and L.N. prepared the database. P.J.D. analysed the data with input from M.S. P.J.D. and M.S. drafted the manuscript, and all authors commented on the manuscript.

\section{DATA ACCESSIBILITY}

Data on network metrics, location and sampling of the 65 networks are provided in Supporting Information Table S1.

\section{ORCID}

Phillip J. Dugger (iD https://orcid.org/0000-0003-0318-619X Maximilian G. R. Vollstädt (iD https://orcid.org/0000-0001-6209-5955 Matthias Dehling (iD http://orcid.org/0000-0001-9426-045X

\section{REFERENCES}

Almeida-Neto, M., Guimarães, P., Guimarães, P. R., Loyola, R. D., \& Ulrich, W. (2008). A consistent metric for nestedness analysis in ecological systems: reconciling concept and measurement. Oikos, 117, 1227-1239.

Barton, K.(2016). MuMIn: Multi-model inference. RPackage Version.1.15.6. Retrieved from https://CRAN.R-project.org/package=MuMIn

Bascompte, J., \& Jordano, P. (2014). Mutualistic networks. Princeton, NJ: Princeton University Press.

Bascompte, J., Jordano, P., Melián, C. J., \& Olesen, J. M. (2003). The nested assembly of plant-animal mutualistic networks. Proceedings of the National Academy of Sciences of the USA, 100, 9383-9387. https://doi.org/10.1073/pnas.1633576100

Bates, D., Maechler, M., Bolker, B., \& Walker, S. (2015). Fitting linear mixed-effects models using Ime4. Journal of Statistical Software, 67, 1-48. Retrieved from https://www.jstatsoft.org/v67/i01

Beckett, S. J. (2016). Improved community detection in weighted bipartite networks. Royal Society Open Science, 3, 140536. https://doi. org/10.1098/rsos.140536

Bello, C., Galetti, M., Montan, D., Pizo, M. A., Mariguela, T. C., Culot, L., ... Jordano, P. (2017). Atlantic frugivory: A plant-frugivore interaction data set for the Atlantic Forest. Ecology, 98, 1729. https://doi. org/10.1002/ecy.1818

Bender, I. M. A., Kissling, W. D., Blendinger, P. G., Böhning-Gaese, K., Hensen, I., Kühn, I., ... Schleuning, M. (2018). Morphological trait matching shapes plant-frugivore networks across the Andes. Ecography, https://doi.org/10.1111/ecog.03396.

Bender, I. M. A., Kissling, W. D., Böhning-Gaese, K., Hensen, I., Kühn, I., Wiegard, T., ... Schleuning, M. (2017). Functionally specialized birds respond flexibly to seasonal changes in fruit availability. Journal of Animal Ecology, 86, 800-811.

Bersier, L., Banašek-Richter, C., \& Cattin, M. (2002). Quantitative descriptors of food-web matrices. Ecology, 83, 2394-2407. https://doi. org/10.1890/0012-9658(2002)083[2394:QDOFWM]2.0.CO;2

Blendinger, P. G., Martín, E., Acosta, O. O., Ruggera, R. A., \& Aráoz, E. (2016). Fruit selection by Andean forest birds: Influence of fruit functional traits and their temporal variation. Biotropica, 48, 677-686. https://doi.org/10.1111/btp.12329
Blüthgen, N., Fründ, J., Vázquez, D. P., \& Menzel, F. (2008). What do interaction network metrics tell us about specialization and biological traits? Ecology, 89, 3387-3399. https://doi.org/10.1890/07-2121.1

Blüthgen, N., Menzel, F., \& Blüthgen, N. (2006). Measuring specialization in species interaction networks. BMC Ecology, 6, 9. https://doi. org/10.1186/1472-6785-6-9

Blüthgen, N., Menzel, F., Hovestadt, T., Fiala, B., \& Blüthgen, N. (2007). Specialization, constraints, and conflicting interests in mutualistic networks. Current Biology, 17, 341-346.

Burnham, K. P., \& Anderson, D. R. (2002). Model selection and multimodel inference: A practical information-theoretic approach. New York, NY: Springer.

Campos-Arceiz, A., \& Blake, S. (2011). Megagardeners of the forest-The role of elephants in seed dispersal. Acta Oecologica, 37, 542-553. https://doi.org/10.1016/j.actao.2011.01.014

Carlucci, M. B., Seger, G. D. S., Sheil, D., Amaral, I. L., Chuyong, G. B., Ferreira, L. V., ... Duarte, L. D. S. (2017). Phylogenetic composition and structure of tree communities shed light on historical processes influencing tropical rainforest diversity. Ecography, 40, 521-530. https://doi.org/10.1111/ecog.02104

Carvalho, C. S., Galetti, M., Colevatti, R. G., \& Jordano, P. (2016). Defaunation leads to microevolutionary changes in a tropical palm. Scientific Reports, 6, 31957. https://doi.org/10.1038/srep31957

Chancellor, R. L., Rundus, A. S., \& Nyandwi, S. (2017). Chimpanzee seed dispersal in a montane forest fragment in Rwanda. American Journal of Primatology, 79, e22624. https://doi.org/10.1002/ajp.22624

Clements, J. F., Schulenberg, T. S., Iliff, M. J., Roberson, D., Fredericks, T. A., Sullivan, B. L., \& Wood, C. L. (2016). The eBird/Clements checklist of birds of the world. Version 2016. https://www.birds.cornell.edu/ clementschecklist/

Cordeiro, N. J., \& Howe, H. F. (2003). Forest fragmentation severs mutualism between seed dispersers and an endemic African tree. Proceedings of the National Academy of Sciences of the USA, 100, 14052-14056. https://doi.org/10.1073/pnas.2331023100

Correia, M., Timóteo, S., Rodríguez-Echeverría, S., Mazars-Simon, A., \& Heleno, R. (2016). Refaunation and the reinstatement of the seeddispersal function in Gorongosa National Park. Conservation Biology, 31, 76-85. https://doi.org/10.1111/cobi.12782

Dalsgaard, B., Schleuning, M., Maruyama, P. K., Dehling, D. M., Sonne, J., Vizentin-Bugoni, J., ... Rahbek, C. (2017). Opposed latitudinal patterns of network-derived and dietary specialization in avian plantfrugivore interaction systems. Ecography, 40, 1395-1401. https://doi. org/10.1111/ecog.02604

Dehling, D. M., Jordano, P., Schaefer, H. M., Böhning-Gaese, K., \& Schleuning, M. (2016). Morphology predicts species' functional roles and their degree of specialization in plant-frugivore interactions. Proceedings of the Royal Society B: Biological Sciences, 283, 2015.2444.

Dormann, C. F., Gruber, B., \& Fruend, J. (2008). Introducing the bipartite package: Analysing ecological networks. R News, 8, 8-11.

Dormann, C. F., \& Strauss, R. (2014). A method for detecting modules in quantitative bipartite networks. Methods in Ecology and Evolution, 5, 90-98. https://doi.org/10.1111/2041-210X.12139

Dunning, J. B. Jr. (2007). CRC handbook of avian body masses (2nd ed.). Boca Raton, FL: CRC Press.

Escribano-Ávila, G., Lara-Romero, C., Heleno, R. H., \& Traveset, A. (2018). Tropical seed dispersal networks: Emerging patterns, biases, and keystone species traits. In W. Dattilo \& V. Rico-Gray (Eds.), Ecological networks in the tropics. Berlin, Germany: Springer.

Farwig, N., Böhning-Gaese, K., \& Bleher, B. (2006). Enhanced seed dispersal of Prunus africana in fragmented and disturbed forests? Oecologia, 147, 238-252. https://doi.org/10.1007/s00442-005-0288-9

Fleming, T. H., Breitwisch, R., \& Whitesides, G. H. (1987). Patterns of tropical vertebrate frugivore diversity. Annual Review of Ecology and Systematics, 18, 91-109. https://doi.org/10.1146/annurev. es.18.110187.000515 
Fricke, E. C., Tewksbury, J. K., \& Rogers, H. S. (2018). Defaunation leads to interaction deficits, not interaction compensation, in an island seed dispersal network. Global Change Biology, 24, e190-e200. https://doi. org/10.1111/gcb.13832

Fricke, E. C., Tewksbury, J. J., Wandrag, E. M., \& Rogers, H. S. (2017). Mutualistic strategies minimize coextinction in plant-disperser networks. Proceedings of the Royal Society B: Biological Sciences, 284, 20162302.

Galetti, M., Guevara, R., Côrtes, M. C., Fadini, R., Von Matter, S., Leite, A. B., ... Jordano, P. (2013). Functional extinction of birds drives rapid evolutionary changes in seed size. Science, 340, 1086-1090. https:// doi.org/10.1126/science.1233774

Guaraldo, A. C., Boeni, B. O., \& Pizo, M. A. (2013). Specialized seed dispersal in epiphytic cacti and convergence with mistletoes. Biotropica, 45, 465-473. https://doi.org/10.1111/btp.12041

Guimarães, P. R., Galetti, M., \& Jordano, P. (2008). Seed dispersal anachronisms: Rethinking the fruits extinct megafauna ate. PLoS One, 3, e1745. https://doi.org/10.1371/journal.pone.0001745

Guimarães, P. R., Jordano, P., \& Thompson, J. N. (2011). Evolution and coevolution in mutualistic networks. Ecology Letters, 14, 877-885. https://doi.org/10.1111/j.1461-0248.2011.01649.x

IUCN. (2016). The IUCN red list of threatened species. Version 2016-1. http://www.iucnredlist.org

Jansson, R., \& Davies, T. J. (2008). Global variation in diversification rates of flowering plants: Energy vs. climate change. Ecology Letters, 11, 173-183.

Jordano, P. (2000). Fruits and frugivory. In M. Fenner (Ed.), Seeds: The ecology of regeneration in plant communities (2nd ed., pp. 125-166). Wallingford, UK: CABI Publishing.

Kissling, W. D., Böhning-Gaese, K., \& Jetz, W. (2009). The global distribution of frugivory in birds. Global Ecology and Biogeography, 18, 150-162. https://doi.org/10.1111/j.1466-8238.2008.00431.x

Kissling, W. D., Rahbek, C., \& Böhning-Gaese, K. (2007). Food plant diversity as broad-scale determinant of avian frugivore richness. Proceedings of the Royal Society B: Biological Sciences, 274, 799-808. https://doi.org/10.1098/rspb.2006.0311

Kissling, W. D., \& Schleuning, M. (2015). Multispecies interactions across trophic levels at macroscales: Retrospective and future directions. Ecography, 38, 346-357. https://doi.org/10.1111/ecog.00819

Martín-Gonzalez, A. M., Dalsgaard, B., Nogués-Bravo, D., Graham, C. H., Schleuning, M., Maruyama, P. K., ... Martinez, N. D. (2015). The macroecology of phylogenetically structured hummingbird-plant networks. Global Ecology and Biogeography, 24, 1212-1224. https:// doi.org/10.1111/geb.12355

Mello, M. A. R., Rodrigues, F. A., da Fontoura Costa, L., Kissling, W. D., Şekercioğlu, Ç. H., Marquitti, F. M. D., \& Kalko, E. K. V. (2014). Keystone species in seed dispersal networks are mainly determined by dietary specialization. Oikos, 124, 1031-1039. https://doi. org/10.1111/oik.01613

Neuschulz, E. L., Botzat, A., \& Farwig, N. (2011). Effects of forest modification on bird community composition and seed removal in a heterogeneous landscape in South Africa. Oikos, 120, 1371-1379. https:// doi.org/10.1111/j.1600-0706.2011.19097.x

Neuschulz, E. L., Mueller, T., Schleuning, M., \& Böhning-Gaese, K. (2016). Pollination and seed dispersal are the most threatened processes of plant regeneration. Scientific Reports, 6, https://doi.org/10.1038/ srep29839.

Peres, C. A., Emilio, T., Schietti, J., Desmouliè, S. J. M., \& Levi, T. (2016). Dispersal limitation induces long-term biomass collapse in overhunted Amazonian forests. Proceedings of the National Academy of Sciences of the USA, 113, 892-897. https://doi.org/10.1073/ pnas.1516525113

Poulsen, J. R., Clark, C. J., \& Palmer, T. M. (2013). Ecological erosion of an Afrotropical forest and potential consequences for tree recruitment and forest biomass. Biological Conservation, 163, 122-130. https:// doi.org/10.1016/j.biocon.2013.03.021

$R$ Core Team. (2016). R: A language and environment for statistical computing. Vienna, Austria: R Foundation for Statistical Computing.

Ruggera, R. A., Blendinger, P. G., Gomez, M. D., \& Marshak, C. (2016). Linking structure and functionality in mutualistic networks: Do core frugivores disperse more seeds than peripheral species? Oikos, 125, 541-555. https://doi.org/10.1111/oik.02204

Rumeu, B., Devoto, M., Traveset, A., Olesen, J. M., Vargas, P., Nogales, M., \& Heleno, R. (2017). Predicting the consequences of disperser extinction: Richness matters the most when abundance is low. Functional Ecology, 31, 1910-1920. https://doi. org/10.1111/1365-2435.12897

Schleuning, M., Fründ, J., \& García, D. (2015). Predicting ecosystem functions from biodiversity and mutualistic networks: An extension of trait-based concepts to plant-animal interactions. Ecography, 38, 380-392. https://doi.org/10.1111/ecog.00983

Schleuning, M., Fründ, J., Klein, A., Abrahamczyk, S., Alarcón, R., Albrecht, M., ... Blüthgen, N. (2012). Specialization of mutualistic interaction networks decreases toward tropical latitudes. Current Biology, 22, 1925-1931. https://doi.org/10.1016/j.cub.2012.08.015

Schleuning, M., Ingmann, L., Strauß, R., Fritz, S. A., Dalsgaard, B., Dehling, D. M., Dormann, C. F. (2014). Ecological, historical, and evolutionary determinants of modularity in weighted seed-dispersal networks. Ecology Letters, 17, 454-463. https://doi.org/10.1111/ele.12245

Sebastián-González, E. (2017). Drivers of species' role in avian seed-dispersal mutualistic networks. Journal of Animal Ecology, 86, 878-887. https://doi.org/10.1111/1365-2656.12686

Sebastián-González, E., Dalsgaard, B., Sandel, B., \& Guimarães, P. R. Jr. (2015). Macroecological trends in nestedness and modularity of seed-dispersal networks: Human impact matters. Global Ecology and Biogeography, 24, 293-303. https://doi.org/10.1111/geb.12270

Snow, D. W. (1981). Tropical frugivorous birds and their food plants: A world survey. Biotropica, 13, 1-14. https://doi.org/10.2307/2387865

Terborgh, J., Davenport, L. C., Niangadouma, R., Dimoto, E., Mouandza, J. C., Schultz, O., \& Jaen, M. R. (2016). The African rainforest: Odd man out or megafaunal landscape? African and Amazonian forests compared. Ecography, 39, 187-193. https://doi.org/10.1111/ecog.01643

Timóteo, S., Albino Ramos, J., Vaughan, I. P., \& Memmott, J. (2016). High resilience of seed dispersal webs highlighted by the experimental removal of the dominant disperser. Current Biology, 26, 910-915. https://doi.org/10.1016/j.cub.2016.01.046

Traveset, A., Tur, C., Trøjelsgaard, K., Heleno, R., Castro-Urgal, R., \& Olesen, J. M. (2016). Global patterns in pollination networks in island and continental areas. Global Ecology and Biogeography, 25, 880-890.

Vázquez, D. P., Melián, C. J., Williams, N. M., Blüthgen, N., Krasnov, B. R., \& Poulin, R. (2007). Species abundance and asymmetric interaction strength in ecological networks. Oikos, 116, 1120-1127. https://doi. org/10.1111/j.0030-1299.2007.15828.x

Vázquez, D. P., Morris, W. F., \& Jordano, P. (2005). Interaction frequency as a surrogate for the total effect of animal mutualists on plants. Ecology Letters, 8, 1088-1094. https://doi. org/10.1111/j.1461-0248.2005.00810.x

Vidal, M. M., Hasui, E., Pizo, M. A., Tamashiro, J. Y., Silva, W. R., \& Guimarães, P. R. (2014). Frugivores at higher risk of extinction are the key elements of a mutualistic network. Ecology, 95, 3440-3447. https://doi.org/10.1890/13-1584.1

De Vivo, M., \& Carmignotto, A. P. (2004). Holocene vegetation change and the mammal faunas of South America and Africa. Journal of Biogeography, 31, 943-957. https://doi. org/10.1111/j.1365-2699.2004.01068.x

Vollstädt, M. G. R., Ferger, S. W., Hemp, A., Howell, K. M., Töpfer, T., Böhning-Gaese, K., \& Schleuning, M. (2017). Direct and indirect effects of climate, human disturbance and plant traits on avian 
functional diversity. Global Ecology and Biogeography, 26, 963-972. https://doi.org/10.1111/geb.12606

Wilman, H., Belmaker, J., Simpson, J., de la Rosa, C., Rivadeneira, M. M., \& Jetz, W. (2014). EltonTraits 1.0: Species-level foraging attributes of the world's birds and mammals. Ecology, 95, 2027.

Zanata, T. B., Dalsgaard, B., Passos, F. C., Cotton, P. A., Ropper, J. J., Maruyama, P. L., ... Varassin, I. G. (2017). Global patterns of interaction specialization in bird-flower networks. Journal of Biogeography, 44, 1891-1910. https://doi.org/10.1111/jbi.13045

\section{BIOSKETCH}

This meta-analysis was initiated by a team of researchers at the Frugivores and Seed Dispersal Symposium and Workshop in South Africa in 2015.

\section{SUPPORTING INFORMATION}

Additional supporting information may be found online in the Supporting Information section at the end of the article.

How to cite this article: Dugger PJ, Blendinger PG, BöhningGaese K, et al. Seed-dispersal networks are more specialized in the Neotropics than in the Afrotropics. Global Ecol

Biogeogr. 2019;28:248-261. https://doi.org/10.1111/ geb.12833 